In conclusion we reiterate some of the main clinical features of epiglottitis. (1) In general the patients are children aged 2-7 years. (2) There is rapid progression from the first mild respiratory symptoms to severe illness, with pronounced dysphagia and drooling, stridor, muffling of the voice, bull neck (in some cases), and such deterioration of the general condition that the terms "shock," "prostration," and "collapse" have been used by various authors. (3) There is no time to spare, and the giving of parenteral antibiotics, admission to hospital, and the establishment of an artificial airway are urgently needed life-saving measures.

\section{ADDENDUM}

Three more children with haemophilus epiglottitis were admitted to the Infirmary in July and September 1971. Their ages were 3,2 , and $1 \frac{1}{2}$ years. Two were treated successfully. One died following a period of apnoea which occurred very soon after his admission, before the right diagnosis had been made.

For permission to report these cases we are grateful to Dr. H. L. Ellis, Dr. B. D. Bower, Mr. B. H. Colman, and Mr. W. S. Lund, the consultants under whose care the patients were admitted. We are also indebted to other colleagues in the departments of paediatrics and otolaryngology, to Dr. R. H. Cowdell and Dr. D. J. de Sa for the necropsy reports, and to the patients' family doctors.
Requests for reprints should be addressed to Dr. D. C. Turk, Gibson Laboratories, Radcliffe Infirmary, Oxford OX2 6HE.

\section{References}

${ }^{1}$ Sinclair, S. E., fournal of the American Medical Association, 1941, 117,

${ }^{2}$ Alexander, H. E., Ellis, C., and Leidy, G., fournal of Pediatrics, 1942, 20, 673 .

3 Rabe, E. F., Pediatrics, 1948, 2, 255, 559

4 Baxter, J. D., Laryngoscope, 1967, 77, 1358

${ }^{5}$ Miller, A. H., Laryngoscope, 1948, 58, 541 .

- Neffson, A. H., Acute Laryngotracheobronchitis. New York, Grune and Stratton, 1949.

${ }^{7}$ Berenberg, W., and Kevy, S., New England fournal of Medicine, 1958, 258, 870 .

8 Phelan, P. D., and Williams, H. E., British Medical fournal, 1968, 4, 455.

8 Phelan, P. D., and Williams, H. E., British Medical fournal, 1968,

10 Jones, H. M., and Camps, F. E., Practitioner, 1957, 178,

11 Andrew, J. D., Tandon, O. P., and Turk, D. C., British Medical fournal, Andrew, J. D., Tandon, O. P., and Turk, D. C., British Medical fournal,
1968, 3, 524.

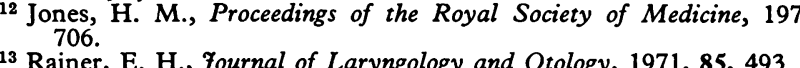

${ }_{14}$ Russell, G., Practitioner, 1971, 206, 781.

${ }^{5}$ Turk, D. C., and Green, C. A., Fournal of Clinical Pathology, 1964, 17, 294.

16 Green, M., and Fousek, M. D., Pediatrics, 1957, 19, 80.

17 Gold, A. J., Lieberman, E., and Wright, H. T., fournal of Pediatrics, $1969,74,779$.

18 Coleman, S. J., Auld, E. B., Connor, J. D., Roseman, S. B., and Warren, G. H., Fournal of Pediatrics, 1969, 74, 781 .

19 Turk, D. C., and May, J. R., Haemophilus Influenzae: its Clinical Importance, p. 13. London, English University Press, 1967.

\title{
Measurement in Medicine
}

\section{Experiences with Outpatient Medical Questionnaires}

\author{
G. H. HALL
}

British Medical fournal, 1972, 1, 42-45

Five years ago I began to use a questionnaire in the medical outpatient department. The original objectives were to reduce the time spent in routine questioning and to spend more time on analysis of the primary symptoms. Since then I have modified the questionnaire several times in the light of experience and have come to use the forms as guides to diagnosis. This paper gives an account of my experiences.

\section{Material and Methods}

There are two clinics a week, each lasting about three hours. About 650 new patients attend each year. The crude diagnostic breakdown is shown in Table I. The waiting time for a new patient is three to four weeks. The questionnaire is sent to the patient with his appointment and he is asked to complete it before coming to the clinic. Before seeing the patient I read the referral letter (usually from a general practitioner, occasionally from fellow specialists) and glance at the questionnaire. I then discuss the main complaint with the patient and

Royal Devon and Exeter Hospital, Exeter EX1 1PQ

G. H. HALL, M.D., M.R.C.P., Physician deal with affirmative answers on the form. The completed form is filed with the case notes. Recently I have adopted a similar routine with my private patients.

TABLE I-Diagnostic Analysis of 631 new Outpatients seen during March 1970 to March 1971

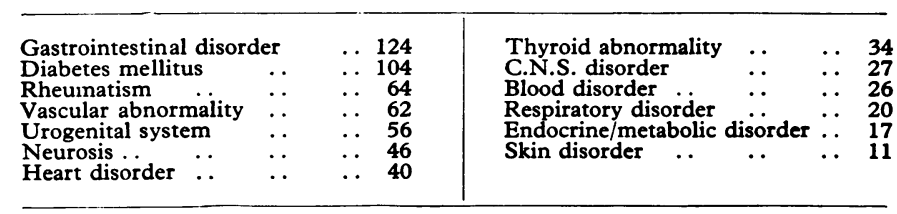

\section{Results}

The first form was modelled on a rubber stamp I had previously been using, and the answers were filled in by me. A brief explanation of the purposes of the form was followed by basic data and a series of questions with alternative possible answers. The appropriate answer was to be underlined. Spaces were left for remarks and past history and a table for family history, based on that used by insurance companies, was included.

I soon found that no objection was raised by the patients to the completion of these forms and that relatively many of them were able to answer the questions sensibly. I was spared the time and tedium of routine questioning, and the way in 
which the forms were completed often gave useful insight into the education and personality of the patients.

The successful introduction of the first form stimulated

BXETER \& MID-DEVON HOSPITAIS MATAGEMIENT CONCITUEES

ROYAL DEVON \& EXETERR HOSPTTAL

Out Patients - Dr. G.B. Ba

Wo are trying to find waye of roduoing the malting timo, both for appointmonte and in the clinic. If you can completo this form it will belp us to do this. Simply fill in the blank specos and ring the appeopriate answer, "Yos" or "Ylo" to the questions. Do this bofare you cone to the olinio, and bring the far

TAMB

MATN COMPIAIMS: 1. JGAK NEN

2. ISMEATHCES SEC

AGE $\quad 43$

SIBCE MID VANuAKY

3. HEUH TUITSS

SDICE

PRESTATT ATD PAST OCCUPATIOIS

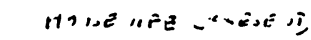

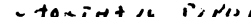

$$
\begin{aligned}
& \text { ghunt } \\
& \text { Manis, - 1 - t, Mroe-s, inito. }
\end{aligned}
$$

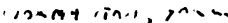

$$
\begin{aligned}
& \text { Hovamia Fe-def. ? came }
\end{aligned}
$$

PAST IILUTESSES: 10.

PAST OPERATTONS, 11 .

\section{IF THES LAST 3 Moirtas BAVE YOO HAD ANT:-}

12. Lose of woight?

13. Gsin in woight?

15. Constipation?

16. Diarrhoea?

7. Pain in the tromer?

18. Trouble with your wator?

20. Trooblo in ool your of wrine?

21. Change in your porlode?

22. Shortmoes of breath?

23. Pain in the abeat?

24. Headeabos?

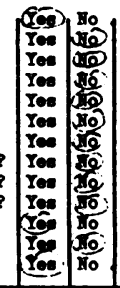

25. Woaknoses or tirodnoses?

27. Tublets from youm Dootor?

28. Tublets bought by yourvele?

29. Slooplocenenes?

Extra bus inoses, fanily or

personal werrice?

that do you think is wrons

with you?

What do you think aeveod this?

P. T. 0

\begin{tabular}{|c|c|c|c|c|}
\hline \multirow[b]{2}{*}{ Relative } & \multicolumn{2}{|c|}{ If alive } & \multicolumn{2}{|l|}{ If doad } \\
\hline & 180 & State of Hoalth & 180 at dapth & Cavese of death \\
\hline $\begin{array}{l}\text { Father } \\
\text {.......... }\end{array}$ & & & 66 & Corenary Triambos: \\
\hline $\begin{array}{l}\text { Mother } \\
\text {............ }\end{array}$ & 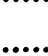 & & 44 & Pne umonia \\
\hline $\begin{array}{l}\text { Brothers } \\
\text { …......... }\end{array}$ & $\cdots \cdots$ & a & & •................. \\
\hline $\begin{array}{l}\text { Siatorn } \\
\text {............ }\end{array}$ & $\begin{array}{l}55 \\
\ldots\end{array}$ & & & \\
\hline $\begin{array}{l}\text { Childaren } \\
\text {............ }\end{array}$ & $\begin{array}{l}18 \\
1.4 .\end{array}$ & $\begin{array}{l}\text { NORMAL } \\
\ldots . . . . . . . . . . .\end{array}$ & & $\cdots \cdots \cdots \cdots \cdots \cdots$ \\
\hline
\end{tabular}

FAMILY HISTORY

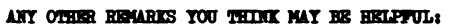

FOR OFries USB OnIS

Dato Attonding

Provistional dinomosis
Hoopital number

Tinal diroposelo me to devise a more comprehensive questionnaire including data on occupation and dwelling places and a wider range of questions dealing with what I thought were the commoner conditions met in the clinic. I hoped that inquiries about medication and the patient's own view of his illness might be informative, but this proved not to be the case. Providing a Yes/No style of question was designed to simplify the answering procedure, but the typographical format proved unfortunate. The form was therefore rearranged (Fig. 1) to place the questions and answers more closely together.

By this time another benefit became apparent-that patients were often willing to give information in writing which they were reluctant to impart face to face. As an example I quote verbatim a touching autobiography of a patient who was tongue-tied at interview.

"This disc trouble started in 1952, went to Mrs. B. the osteopath at $\mathrm{P}$ — who did me a lot of good but had to keep going back for Electric Treatment which did me a lot of good and helped me a great deal, but made me want sex which of course I could not have as My Husband did not have intercourse with me once in the whole of the eleven years I was married to him, but to my shame and ignorants I lost my virginity in my early twentys, but never had the full intercourse and flour from any man. So have had a very frustrating life. So hope you will understand and get me right, have suffered so much pain."

Furthermore, an admission of intimate difficulties on the form would be taken as an invitation to discuss them further at interview without embarrassing preliminaries.

As experience accumulated certain omissions and redundancies became obvious. For example, no mention was made of thirst or of joint pains, both common complaints in common conditions. I was also intrigued by the possibility of constructing a comprehensive diagnostic questionnaire, though I had been discouraged by the formidable size and appearance of the ones available-for example, the Cornell Medical Index. Before reconstructing my own form, however, it was clearly necessary to analyse systematically both the symptoms and the diagnoses of the patients attending my clinic. To do this the available case notes had to be withdrawn from the records department and the primary complaints and diagnoses transcribed on to the questionnaires.

The results of this exercise were surprising in their banality. Like most clinicians I tend to be interested by the exceptional and the rare and was therefore rather disappointed to find that the vast majority of my outpatient work indeed dealt with common conditions. Peptic ulcer, diabetes, rheumatism, neurosis, and cardiovascular insufficiency made up more than $80 \%$ of my cases.

I decided to test the ability of the form to distinguish the four conditions most often encountered and to attempt to devise an improved list of questions if necessary. Altogether 257 questionnaires were retrieved from the 307 traceable case notes of the 333 new patients who attended between January and June 1968. Because more than one diagnosis would confuse the issue only the 165 questionnaires from patients with one diagnosis were studied. The commonest conditions in this group were : peptic ulcer in 21 cases (13\%), diabetes in 19 cases (11\%), neurosis in 18 cases (11\%), and rheumatism in 17 cases $(10 \%)$.

To augment these numbers before statistical analysis extra forms from patients seen in 1967 with these conditions were added. The proportion of positive answers to questions 12-30 was ascertained (Fig. 2). The differences of profile, easily detected by eye, were shown to be significantly different by the $\chi^{2}$ test-diabetes and rheumatism, P 0.025; diabetes and neurosis, P 0.05; rheumatism and neurosis, $P$ 0.005; duodenal ulcer and diabetes, P 0.005; duodenal ulcer and rheumatism $P$ 0.001; duodenal ulcer and neurosis, $P>0.1$. It was clear, however, that many fewer questions would have sufficed to distinguish them. Reference to the original case notes gave the spontaneous complaints listed in Table II. 

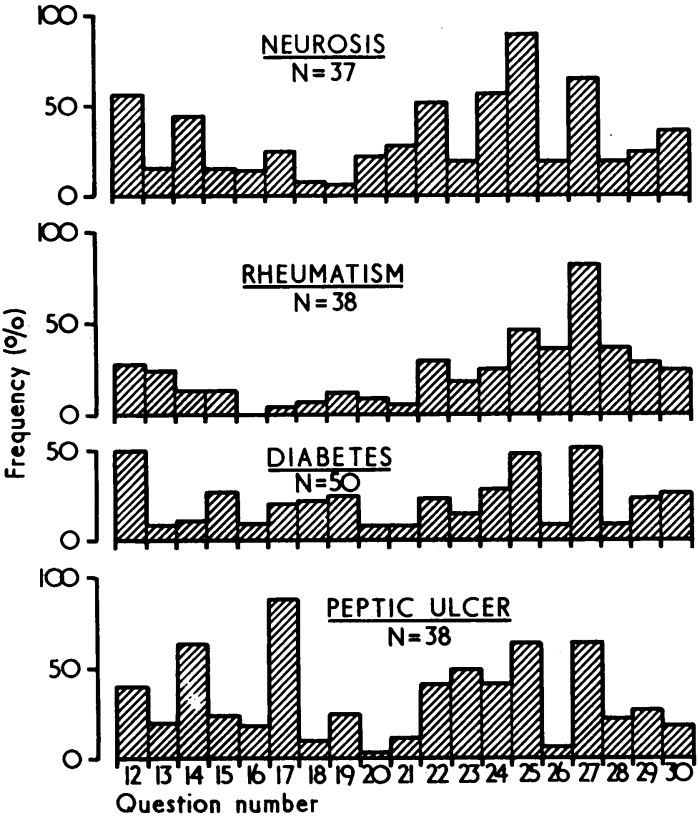

FIG. 2-Frequency of positive answers to questions 12-30 (forms 2 and 3 ) in four conditions. $N=$ Number of patients in each group.

TABLE II-Percentage of Positive Answers found in Original Case Notes

\begin{tabular}{|c|c|c|c|c|c|}
\hline & & $\begin{array}{l}\text { Duodenal } \\
\text { Ulcer }\end{array}$ & Rheumatism & Neurosis & $\begin{array}{l}\text { Diabetes } \\
\text { Mellitus }\end{array}$ \\
\hline $\begin{array}{l}\text { Abdominal pain } \\
\text { Vomiting } \ldots \\
\text { Pain in limbs } \ldots \\
\text { Fatigue } \quad . .\end{array}$ & $\begin{array}{l}\ldots \\
\cdots \\
\cdots\end{array}$ & $\begin{array}{l}85 \\
50\end{array}$ & 100 & $\begin{array}{l}11 \\
55\end{array}$ & 18 \\
\hline
\end{tabular}

The additional specific question about excessive thirst would greatly help definition of the diabetic group. With such considerations in mind the latest questionnaire (Fig. 3) was drawn up. In practice this still remains imperfect, and I shall delete the questions to which the proportions of positive answers are either less than $20 \%$ or more than $80 \%$. The question "Why did you go and see your doctor?" has proved much more informative than the old "Main complaint?". The answers to the latter were usually couched in hearsay medical terms and of little value. I shall in future include questions on smoking and drinking habits (as included on the original form), and the suffix P.T.O. is vital if the reverse of the form is to be completed in all instances.

\section{Discussion}

I have found that questionnaires are more acceptable to patients than to doctors. The latter generally reject the idea as too mechanistic and erosive of the mystique of anamnesis. I would counter this objection by my observation that by using the form I can spend relatively more time discussing the principal symptoms without getting stultified and stupefied by the necessary chore of routine questioning. It is surprising, perhaps, that so little is written about the rationalization of history taking, since it comprises such a large part of a physician's work. Certainly the patient should be allowed to tell his story in his own way, but his account can be written just as well as spoken, and indeed may gain in clarity from being written. I believe that it is essential, however, that the questionnaire be completed at home so that the patient has plenty of time to do it properly. Oral examinations usually give worse results than written examinations because of the unfamiliar environment and pressure of time.

Ideally, questionnaires should be simple, unambiguous, comprehensive, and discriminatory, but it is impossible for

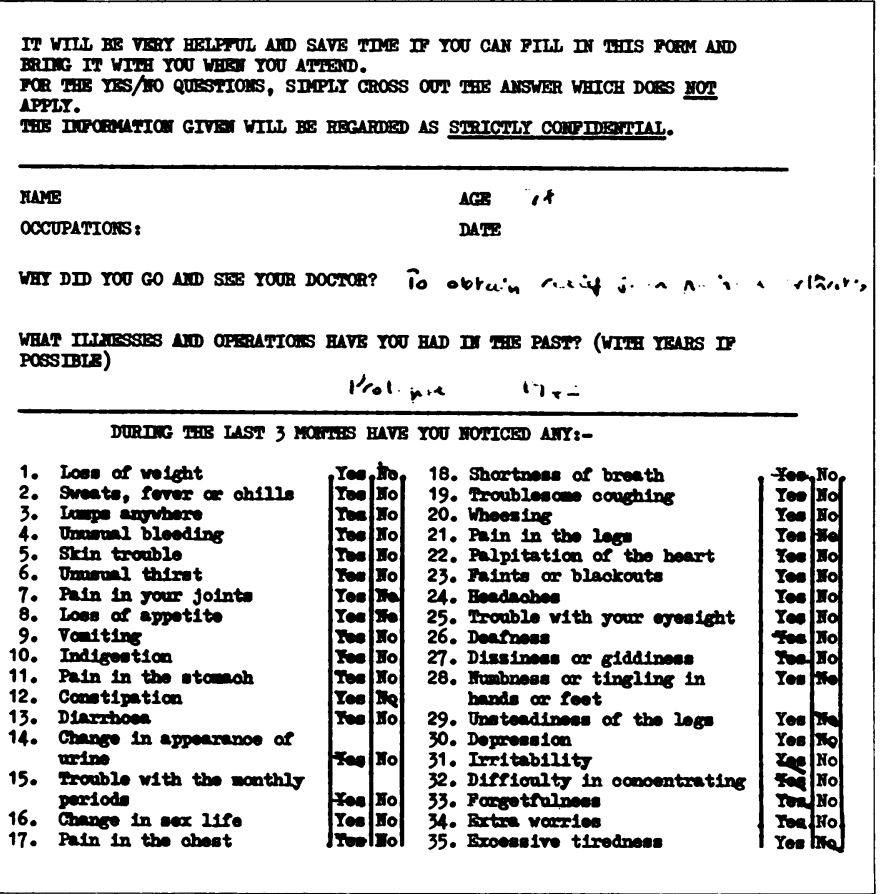

\begin{tabular}{|c|c|c|c|c|}
\hline \multirow{2}{*}{$\begin{array}{l}\text { PLYWY HESTOEY } \\
\text { Rolative }\end{array}$} & \multicolumn{2}{|r|}{ If alive } & \multicolumn{2}{|c|}{ If dead } \\
\hline & 180 & State of Hoalth & $\Delta 80$ at death & Caves of deats \\
\hline Fathor & & & 47 & \\
\hline rother & $\bullet \bullet$ & ....................... & 90 & \\
\hline Brotheres & & & & ............. \\
\hline Siotem & & & & \\
\hline Chllaren & & & & \\
\hline •....... & & ........... & $\cdots$ & $\ldots . . . . . . .$. \\
\hline
\end{tabular}

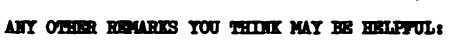

$$
\text { Poov circulation and fidgets }
$$

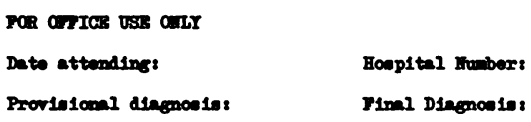

FIG. 3-Current form, front and back.

a form to have all or even more than one of these qualities. It is doubtful, too, whether any single form can suit more than one clinician, so that those who propose to use one will probably have to devise one for themselves.

Answers should be capable of validation. We have to make the assumption that patients and doctors mean the same thing when using the same word. It is not feasible to discuss definitions of every word used in a clinical setting-or any other for that matter-and one has to take as much for granted in this respect while listening as when reading. With a completed form, however, one's attention can be restricted to the affirmative answers, and clarification can be obtained there.

Though I have illustrated how these forms may be used for proleptic diagnosis I have not so far employed them in this way. A preliminary inspection, however, may indicate a need for certain investigations which could usefully be carried 
out before the interview. Furthermore, if patient screening has to be carried out by non-medical personnel, models of this sort may find an application. Questionnaires with a smaller range but greater depth may find a place in differential diagnosis in the subspecialties.

It must be admitted that the procedures described here are unsophisticated and the methods used in drawing up the forms empirical and heuristic. Probably this is unavoidable in a medical context. But any help in the difficult task of categoriza- tion of raw symptom data into manageable medical concepts is not entirely to be despised.

I would like to thank Mr. W. W. Knott, records officer, and his staff for their great help in the production and handling of the questionnaires. The arduous task of record abstraction was carried out by the late Dr. S. Simpson, and the extra secretarial work by Miss J. Brooking and Miss A. Mylles. The case histories recorded in Figs. 1 and 3 are fictional.

\section{Any Questions?}

We publish below a selection of questions and answers of general interest

\section{Precautions for Travel in Northern Scandinavia}

What medical hazards might be encountered when holiday camping in Swedish Lapland and Finmark? What inoculations are necessary, and what drugs might usefully be taken?

In certain areas along the Torne river guests are sometimes served uncooked fish which may be infected by the tapeworm Botriocephalus latus. A few cases of hare-plague (tularemia) occur in northern Scandinavia, but the risk is only very slight of a man contracting this disease. In the past, echinococcosis in reindeer (dogs being the intermediate hosts) was not uncommon, but I consider the risk of this infection occurring nowadays in man to be extremely low. However, travellers should avoid close contact with dogs in Lap communities.

Bears and wolves do occur in northern Scandinavia but far away from roads and camping sites. Mosquitoes are large and plentiful and, with midges, may be troublesome for the traveller when trout- and salmon-fishing in the midnight sun in northern Norway. I have survived some 20 expeditions of exploration in these lonely, wild areas of unspoiled nature and have no hesitation in drinking the water from brooks or rivers. I regard the sum of all the hazards mentioned to be much less than those facing the Mediterranean traveller. There is no need for special drugs except for an insect repellant for the king-size mosquitoes, and no inoculations are necessary. Some people may find an eyemask of help in sleeping in the midnight sun.

Torp, K. H., British Medical Fournal, 1970, 4, 301.

Torp, K. H., World Medical fournal, 1971, 18, 20.

\section{Notes and Comments}

Hydrofluoric Acid Burns.-DR. R. A. Trevethick (British Steel Corporation Special Steels Division, Rotherham, Yorks) writes: Your Expert's answer to this question ("Any Questions?" 28 August, p. 526) quotes the classical treatment which has been generally accepted for many years in this country. The Americans have recently abandoned the use of calcium gluconate injections though still adhering to the use of magnesium oxide paste. The treatment now recommended varies from your Expert's answer in two respects: 1 (1) The area of skin burnt should be deluged in ice cold water if available because of the anaesthetic effect; (2) Soaks of $2 \%$ iced solution of Hyamine 1622 (benzethonium chloride) should be continued for 2-4 hours, and then followed by magnesium oxide paste. Hydrofluoric acid burns are relatively rare and it is difficult to arrange a controlled trial of the methods available. Undoubtedly calcium gluconate does not always produce the desired effect, and the new method deserves a trial.
OUR EXPERT replies: I thank Dr. R. A. Trevethick for his helpful comments on the early treatment of hydrofluoric acid burns with Hyamine 1622 (benzathonium chloride). A few of the high-molecular weight, quaternary ammonium salts, or cationic surface active agents have been used for the initial treatment. These include cetrimide (cetyltrimethyl ammonium bromide), 2 Zephiran (benzalkonium chloride), ${ }^{3}$ and Hyamine (benzathonium chloride). 4 All Americans have not abandoned the use of calcium gluconate and the most recently published American opinion ${ }^{3}$ recommends the use of calcium gluconate for the more severe burns reserving Hyamine for the minor burns.

A fatal dose of Hyamine is estimated ${ }^{5}$ at 1 to $3 \mathrm{~g}$, and this would be equivalent to $50 \mathrm{ml}$ to $150 \mathrm{ml}$ of a $2 \%$ solution. It is known that some substances can be absorbed into the circulation quite readily from a burned surface so that great care has to be taken in choosing any local preparation applied to the surface of a burn. A $0.2 \%$ solution has been recommended for application to hydrofluoric acid burns ${ }^{4}$ but as far as I am aware no blood levels of Hyamine have been performed and there is little guidance as to the exact weight of Hyamine which can be safely applied to the surface of a burn in a given time. Assuming that one molecule of Hyamine (molecular weight 448) combines with one molecule of hydrofluoric acid (molecular weight 20), about 21 . of a $0.2 \%$ solution of Hyamine would theoretically be required to neutralize $1 \mathrm{ml}$ of a $20 \%$ solution of hydrofluoric acid. This is about $4 \mathrm{~g}$ of Hyamine, well above a fatal dose. Only about $20 \mathrm{ml}$ of a $10 \%$ solution of calcium gluconate would be required to have the same effect and this is much safer.

Whether the above theoretical considerations are correct "in vivo" is unknown, but if Hyamine is to be used it would be wise to limit the total dosage given until evidence is obtained as to the toxicity of Hyamine when applied to hydrofluoric acid burns. My reply laid more stress on the general and surgical management of hydrofluoric acid burns because of my doubt as to the effectiveness of the local agents which have been used in the past. However, Hyamine and calcium gluconate are worthy of trial but care should be taken of the dosage.

1 Reinhardt, C. F., Hume, W. G., Linch, A. L., and Wetherhold, J. M., American Industrial Hygiene Association foumal, 1966, 27, 166

2 McColl, J. D., Transactions of the Association of Industrial Medical Officers, 1962, 12, 6.

3 Dibbell, D. G., Iverson, R. E., Jones, W., Laub, D. R., and Madison, M. S., fournal of Bone and foint Surgery, 1970, 52A, 931

Wetherhold, J. M., and Shepherd, F. P., Fournal of Occupational Medicine, 1965, 7, 193.

- Extra Pharmacopoeia, Martindale, 25th edn. London, Pharmaceutical Press, 1967. 